\title{
Monitoring The Bisphosphonate Treatment Holiday
}

\author{
Clare Mumby, Shazli Azmi, Katharine Hayden, Judith Adams, Peter Selby \\ Manchester Royal Infirmary, Central Manchester Hospital Foundation Trust, Manchester, UK.
}

\section{Introduction}

Osteoporosis is the most common bone disorder, leading to fragility fractures and significant morbidity and mortality.

Bisphosphonates are the most commonly used drugs to treat osteoporosis. They are antiresporbtive, reducing bone turnover by inhibiting osteoclast function. Recently there have been concerns over the effects of long term use of bisphosphonates, particularly atypical femoral fractures. Patients are now being offered a 'treatment holiday' after 5-10 years of treatment. The withdrawal phase of bisphosphonate studies have shown residual fracture benefit after stopping treatment but there is no data looking at bone mineral density or bone turnover markers once treatment has stopped.

\section{Purpose}

To monitor the bone turnover marker, amino-terminal propeptide (P1NP) and bone mineral density (BMD) during the bisphosphonate treatment holiday.

\section{Methods}

A retrospective case note review of 68 patients currently undergoing a bisphosphonate treatment holiday. P1NP and BMD were recorded at baseline and at intervals during the treatment holiday. The BMD was recorded as a percentage change to determine clinical significance (least significant difference $=+$ /$3 \%)$.

\section{References}

Eriksen et al. "Update on long-term treatment with bisphosphonates for postmenopausal osteoporosis: A systematic review." Bone 58 (2014): $126-1352$. McClung, Michael, et al. "Bisphosphonate therapy for osteoporosis: benefits, risks, and drug holiday." The American journal of medicine 126.1 (2013): $13-$ 20.

\section{Results}

\begin{tabular}{|l|l|l|l|l|}
\hline Parameters & $\begin{array}{l}\text { Baseline } \\
\mathrm{N}=67\end{array}$ & $\begin{array}{c}\text { Year 1 } \\
\mathrm{N}=67\end{array}$ & $\begin{array}{l}\text { Year 2 } \\
\mathrm{N}=50\end{array}$ & $\begin{array}{l}\text { Year 3 } \\
\mathrm{N}=31\end{array}$ \\
\hline Age & $69.5 \pm 1.5$ & & & \\
\hline Sex (M/F) & $10 / 58$ & & & \\
\hline $\begin{array}{l}\text { Bisphosphonate } \\
\text { Duration (years) }\end{array}$ & $7.1 \pm 3.0$ & & & \\
\hline P1NP ( $\mu$ g/l) & $18.8 \pm 1.2$ & $32.9 \pm 1.5$ & $33.6 \pm 1.9$ & $32.3 \pm 2.2$ \\
\hline
\end{tabular}

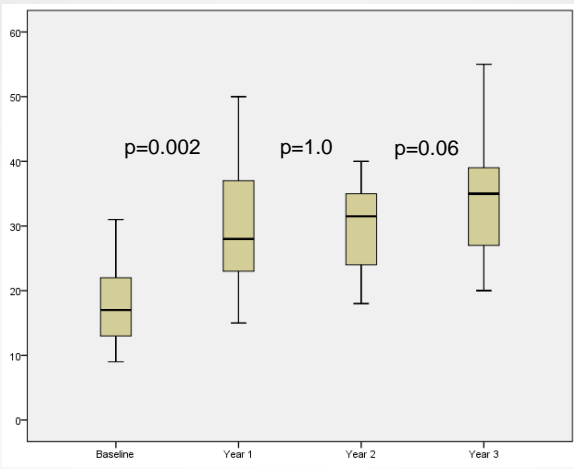

Graph 1: P1NP longitudinal results.

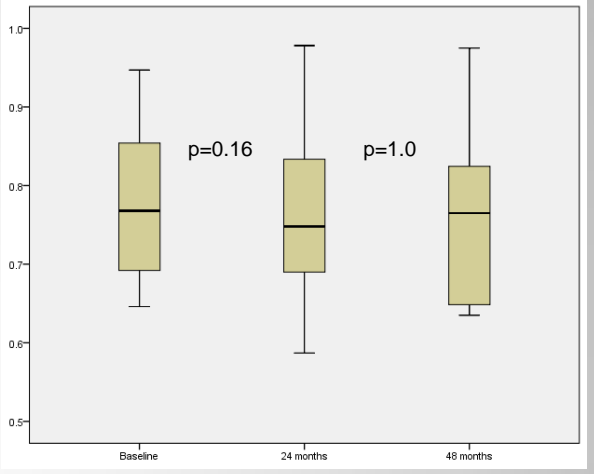

Graph 2: Hip BMD longitudinal results

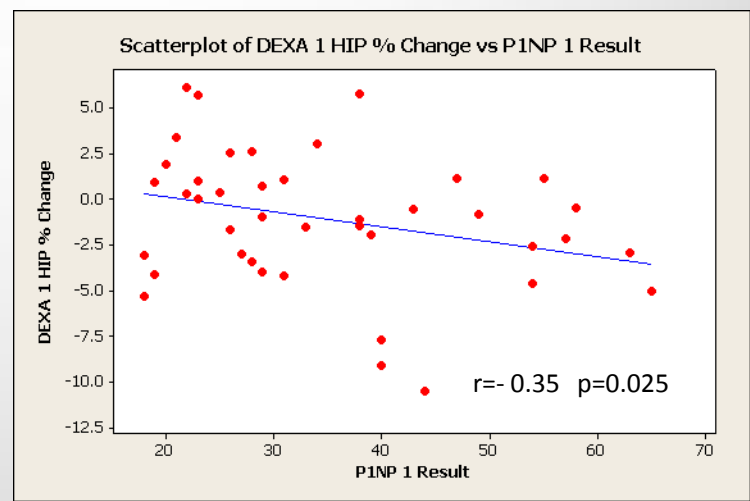

Graph 3: Correlation between the P1NP at 12 months and Hip BMD at 24 month

\section{Conclusion}

After an initial rise in P1NP after stopping the bisphosphonate, P1NP levels then appear to remain stable for at least 3 years. Bone Mineral Density remains clinically stable for at least 24 months. A higher level of P1NP at 12 months may predict the level of bone loss at 24 months. The bisphosphonate treatment holiday is an area that requires further research. 